\title{
Occupation Recommendation with Major Programs for Adolescents
}

\author{
Ankhtuya Ochirbat ${ }^{1}$ \\ National Central University \\ No. 300, Zhongda Rd., Zhongli District, Taoyuan City 32001, Taiwan (R.O.C.) \\ National University of Mongolia \\ P.O.Box -46a/523, 210646, Ikh Surguuliin Gudamj-1, Ulaanbaatar, Mongolia \\ E-mail: ankhaa8@gmail.com

\section{Timothy K.Shih} \\ National Central University \\ No. 300, Zhongda Rd., Zhongli District, Taoyuan City 32001, Taiwan (R.O.C.) \\ E-mail: timothykshih@gmail.com
}

\begin{abstract}
Choosing a major in high school or undergraduate stage is an important decision in the person life. To find students' majors as earlier as possible can help them to choose correct learning direction. Hence, it is essential to build a recommendation system that provides direction and guidance to students. In this regard, this study proposes Occupation Recommendation System with major program of study (ORS), a framework to assist students in the major/occupation selection, to provide the information about contemporary occupations, and to suggest the suitable occupations with major program of study based on their learning style, personality and vocational interests. Collaborative Filtering (CF) methods are employed, namely, a memory-based CF on vocational interest and a model-based $\mathrm{CF}$ on a regression model according to the learning style and the personality. The system provide top 10 occupations for each method respectively. This paper describes the architecture and interface of ORS and shows the experiments with 190 high school students. Moreover, comparisons between recommended majors, suggested majors by parents and students' intended majors are made.
\end{abstract}

International Symposium on Grids and Clouds 2017 -ISGC 2017-

5-10 March 2017

Academia Sinica, Taipei, Taiwan

\section{${ }^{1}$ Speaker}




\section{Introduction}

Students make initial and critical decisions regarding what to study further and which career path to pursue [1]. Many students enter post-secondary education without a clear idea of their major and future career plans. Mismatch of the major choice and lack of processing information through the professional study is one of the reasons to switch the major. Such changes are wasteful in time and resources, and also it is the cause of emotional and financial stresses of students. An approximated twenty to fifty percent of students enter college as undecided; and an approximated seventy-five percent of students change their major at least once before graduation [2]. The obvious practical research question that arises from this problem is, which people are suited for which majors. In addition, it would be useful to understand how students' choice of the academic majors depends on psychological characteristics such as personality characteristics, learning styles, and vocational interests.

While the vocational interest of childhood might be difficult to determine, personality characteristic and learning style can be identified during earlier grades of the students, which are not easy to change. When students learn about their personality, they can be better prepared on their search for a major. Besides, we believe that learning style is one of the influencing factors for students' further successful study through their chosen major since depending on the major choice defines courses that students will take during the professional education. Porter and Umbach [3] highlighted a very important concept that incorrect major choice can affect student learning and satisfaction in educational life, and further can affect his/her job stability, job satisfaction, career opportunities, and rewards in work life later. Finally, even though we have our own interests and desires, in particular, we are affected on the decisions by the environment and the society unknowingly.

Therefore, an aim of this current study is to examine how personalities and learning styles interact to predict the suitable occupation of vocational interest using data mining methods and to identify the relationship between 4 kinds of majors, namely, intended major of the student, suggested major by parents, recommended major through vocational interest using Holland code model, and predicted major based on personalities and learning styles of the students. In addition, we investigated the influence factors for intended majors of students. We demonstrated the automatic occupation recommendation system to counsel and guide students.

\section{Background and Related Work}

\subsection{Factors in major choice}

There are several reasons that influence students' major choice. Past studies show that personality, personal interest, learning style, family and parent influence, career opportunity, future earnings, and job availability are some of the factors that influence students' decision [4$10]$.

Big five personality inventory is a measuring tool of personality; it consists of five factors namely Extraversion, Agreeableness, Openness, Conscientiousness, and Neuroticism [11-13]. Hussain, Abbas, Shahzad, and Bukhari [14] reported that personality plays an important role in the students' major choice. Brown and Cinamon [15] showed that the contribution of Big five personality on the academic decision-making of adolescents with self-efficacy in relation to selecting high school major and outcome expectations. 
Learning style is regarded as a way of learning. Students obtain and process information in different ways based on their strengths and preferences, which means that they have different learning styles. Index of learning style (ILS) evaluates alternates on the four factors namely, Active/Reflective, Sensing/Intuitive, Visual/Verbal, and Sequential/Global [16-18].

People's differences are not only classified through personalities, but also expressed by personal interests and preferences; some people show clear preferences for mechanical activities, whereas others develop hobbies indicating conventional and enterprising activities. Holland code model has 6 types of vocational interests, namely, Realistic, Investigative, Artistic, Social, Enterprising, and Conventional, which yield RIASEC acronym [12, 19-21].

\subsection{Recommendation techniques}

Recommendation Systems (RS) are a subclass of information filtering system that seek to predict the 'rating' or 'preference' that a user would give to an item. RS collect information on the preferences of its users for a set of items (e.g., movies, songs, books, jokes, gadgets, applications, websites, travel destinations and e-learning material). RSs assist and augment this natural social process to help people sift through books, webpages, articles, movies, music, restaurants, jokes, grocery products and so forth to find the most interesting and valuable information for them [22]. There are mainly and commonly used types of it, content based filtering, collaborative filtering, knowledge based filtering and hybridization [23]. We focused on collaborative filtering recommendation methods.

Collaborative Filtering allows users to give ratings about a set of elements (e.g. videos, songs, films, products etc.) then recommendations are made to each user based on information provided by those users $[22,24]$. There are two categories, memory-based and model-based methods. Memory-based methods can be defined as methods that (a) act only on the matrix of user ratings for items and (b) use any rating generated before the referral process (i.e., its results are always updated). Memory-based methods usually employ similarity metrics to obtain the distance between two users, or two items, based on each of their ratios. For model-based methods, recommended objects are selected on models that are trained to identify patterns in the input data; the methods includes probabilistic model, Bayesian classifiers, regression analysis, neural networks, fuzzy systems, genetic algorithms, latent features, and matrix factorization methods $[25,26]$. We considered both memory-based and model-based methods.

\subsection{Career counseling, Major choice and Occupation recommendation in Mongolia}

In Mongolia, the Ministry of Science, Education and Culture (MSEC) is the national and central administrative and authoritative body that formulates national educational policy and sets the standards for each level of formal education. According to the Education Law in the admission, each college/university organizes the enrollments and registrations of entrants, and has own website to provide information of the branch of college/university, limited number of entrants, program name, exam name by subject, score ratio (\%), threshold score. Furthermore, Consortium of Mongolian Universities and Colleges (http://www.cmuc.edu.mn/) supplies the program groups by subjects with score ratio through members of college/university; students can find the program and college/university easily. But there does not have a detail information, only has program and college/university names. 
National Employment Service, Research and Information Center (http://hudulmur.mn/) provides the services that users can check the occupational descriptions, search workplaces or staffs, send/receive the worker to/from foreign country, see statistics and researches of the labor. Moreover, a project entitled "Support for the implementation of the Labor Market Information System and Career Guidance Services in Mongolia" implemented by Millennium Challenge Account Mongolia (MCA-M) organization was to design an integrated Labor Market Information System (LMIS) and Career Guidance System (CGS) in Technical Vocational Education and Training in Mongolia between 21 March 2011 and 16 March 2012. The web portal (www.mergejil.mn) presents occupational descriptions, the schools, and the programs in Technical Vocational Education and Training. Besides, some popular job searching websites in Mongolia are www.biznetwork.mn/jobs, www.joblinksmn.com, www.ezar.mn/zar/, www.zar.mn, www.shuurkhaizar.mn, and www.zarmedee.mn).

According to the S.Enkhtuvshin [27] and B.Bolormaa et al. [28], they stated that Online Automate System, which can provide occupational information including work setting, requirements, tasks to perform, required level of education, skills and competence of the particular majors/occupations and the guidance/counseling for students based on their preferences, are needed. Consequently, the personalized major/occupation automatic recommendation system for general education students is inevitably needed to build.

The research questions derive from this issue is, whether students will study continuously or will find a job directly after the school graduation, how to help them in the occupation/major/job selection. We purposed that the recommendation system provides occupational information including tasks to perform, required skills, knowledge, and ability, required education level, and major studies in each occupation and recommends top 10 occupations to adolescents based on their preferences and interests.

\section{Proposed system}

\subsection{Problem statement}

Due to the rapid development of society, students need counselling session to enable them to choose a suitable occupation. The choice of the occupation has become increasingly complex due to the existence of multiple human abilities which mean each person or human has their ability or skill at the certain area and can be applied to multiple occupations. The main problem of difficulty making the occupation selection among students is they do not know how make decisions and lack of knowledge and information about occupations and majors. It is essential to build the occupation recommendation system for the students with a capacity to meet all the needs where it provide direction and guidance to students in choosing an occupation that suits with their vocational interests and personal characteristics.

\subsection{Architecture}

Occupation Recommendation System (ORS) is to assist adolescents in discovering the occupation interests. General illustration of methods and its interactions is shown in Fig. 1. First, ORS collects personal details from adolescents by registrations and then the system asks adolescents to fill questionnaires in personality, learning style and interest optionally and shows results. Teachers could explain results in personality, learning style and interest based on their 
answers which skills to improve comparing an intended occupation. Adolescents can search intended occupations. The system displays a list of relevant occupations. In the detail of each occupation will show content that consists of related knowledge, skill, required ability, related majors, and required level of education. Second, if there are missing factors, the system will predict it. Third, the recommendation result is generated based on adolescents' dataset namely personal information and results of questionnaires.

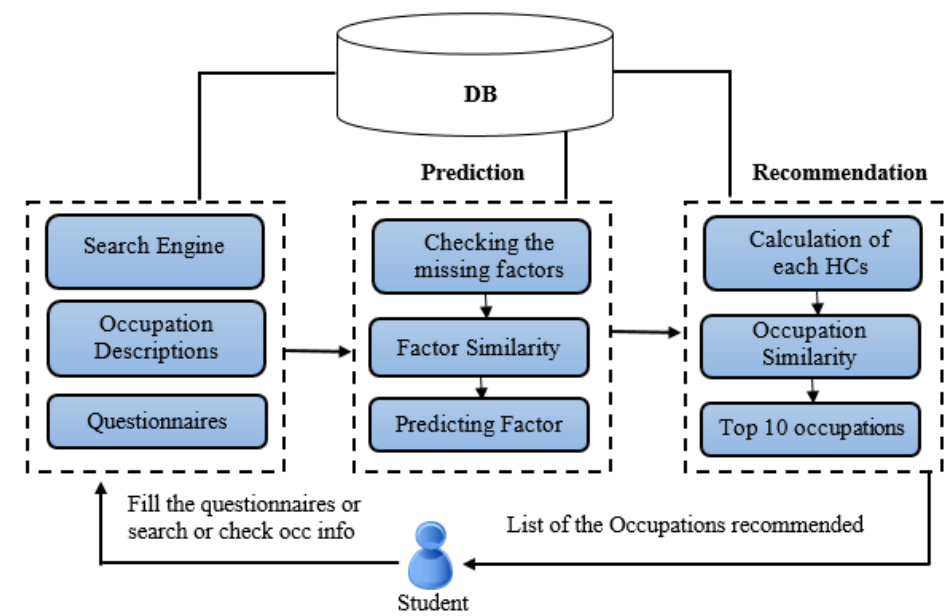

Figure 1: ORS architecture

\subsection{Data collection}

\subsubsection{Participants}

Counselling and guiding on the majors of the students are not well organized, especially in the rural area of Mongolia. Most of the students do not possess adequate information about occupations, what professions can be reached by these occupations, and what kind of skills and abilities are needed for a particular occupation, even some parents are uninformed about the contemporary majors/occupations. Therefore, we chose a sample located in the countryside in Zuunmod city and conducted the experiment during the semesters from 2014/2016 years.

Students $(\mathrm{N}=190)$ enrolled in the last 3 years of the high school were participated in the study. Eighty-one participants were in grade 10, 107 participants were in grade 11, and 2 participants were in grade 12. The participants' age range is from 15 to 19 years with a mean age of 16.41 years $(\mathrm{SD}=.87)$. Fifty-six percentage $(\mathrm{N}=107)$ of the participants were female and $42 \%$ $(\mathrm{N}=80)$ were male while remaining percentage students didn't fill the gender options.

\subsubsection{Measures}

A questionnaire consisted of 4 sections namely, demographic information, inventories of personality, learning style, and vocational interest, is used to collect students' information. The original versions of the inventories were in English as mentioned in the background and related work and then translated by professional translators without affecting the original meaning into Mongolian versions, which the students can understand well.

Demographic information included full name, age, grade, intended major, parents' suggested major. Intended major is the planned and interested major of the student. Suggested major stands for the major suggested to their child by the parent. We asked the students to fill the suggested 
major by the parents, if they discussed about it with the parents before. Besides, occupational codes of intended and suggested majors were examined by two teachers in the field of computer science. Inter-rater reliability between two rates is 0.81 .

Big five inventory (BFI). It [29, 30] was used to assess students' personalities. The BFI has 44 items with responses made on a Likert scale format ranging from strongly disagree $(=1)$ to strongly agree $(=5)$ and measures the five personality factors: Extraversion, Agreeableness, Conscientiousness, Neuroticism, and Openness. Internal consistency reliability of BFI is .85 .

Index of learning style (ILS). It is a self-scoring questionnaire with 44 items for measuring 4 factors [16], which are active/reflective, sensing/intuitive, visual/verbal, and sequential/global. Each learning style factor is combined with 11 item choices, with each option, ' $a$ ' or ' $b$ ', corresponding to one or the other category of the factor. The ' $b$ ' responses are subtracted from the ' $a$ ' responses in each factor to obtain a score ranging from 0 to 11 . Internal consistency reliability of learning styles is .69 .

Vocational Interests. Holland code (HC) model with the 106-item [19, 31] was used as a measure of students' vocational interests. Students rate their level of interest in each occupational description on a Likert scale (strongly dislike to strongly like). There are 6 factors (Realistic, Investigative, Artistic, Social, Enterprising, and Conventional - RIASEC). Scoring the highest 2 or 3 factors are necessary to discover an interested occupation or vocational interest, and a useful description, such as SIC (Social, Investigative, and Conventional), IRC (Investigative, Realistic, and Conventional), etc. Internal consistency reliability of vocational interests is .96. All factors could be seen in Fig. 2.

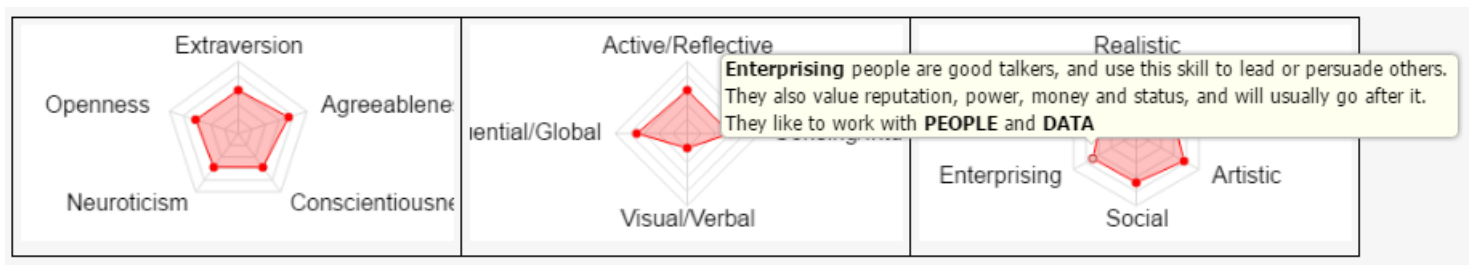

Figure 2: Representations of BFI, LSI, and HC model's Factors

Occupations. There are around 1000 occupations and its descriptions which are used to provide information on occupational data. Vocational interests categorized the occupations according to the HC model's six factors. Each occupation has 40 tasks, 33 knowledge, 6 interests, 35 skills, and 52 abilities as well as its related occupations, major program of study and required level educations (See Fig. 4) and belongs from low to high scores for each domain (task, knowledge, interest, and skill) respectively [32-34].

Major Field of Study. The Classification of Instructional Programs (CIP) is a taxonomic coding scheme of instructional programs [35]. Its purpose is to facilitate the organization, collection, and reporting of fields of study and program completions. There are 47 two-digit series and 1459 instructional program classes to provide the title and the description of major field of study to the students. Further, when students choose the major, they could consider those recommended major program of study according to the occupation they interested. For example, major academic program in Computer Systems Engineers/Architects occupation can be seen in Fig. 3. 


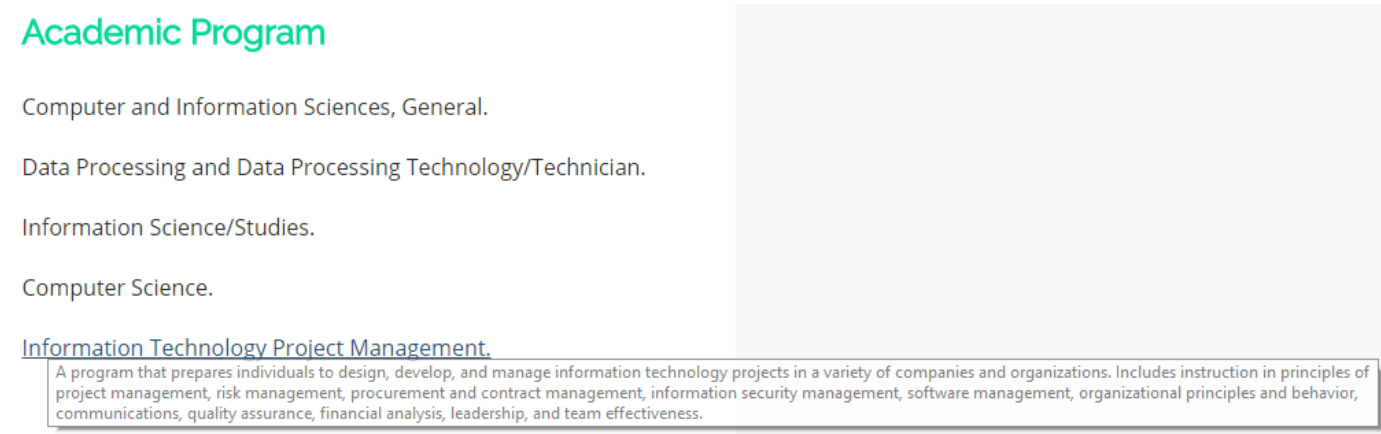

Figure 3: Major Field of study for Computer Systems Engineers/Architects occupation

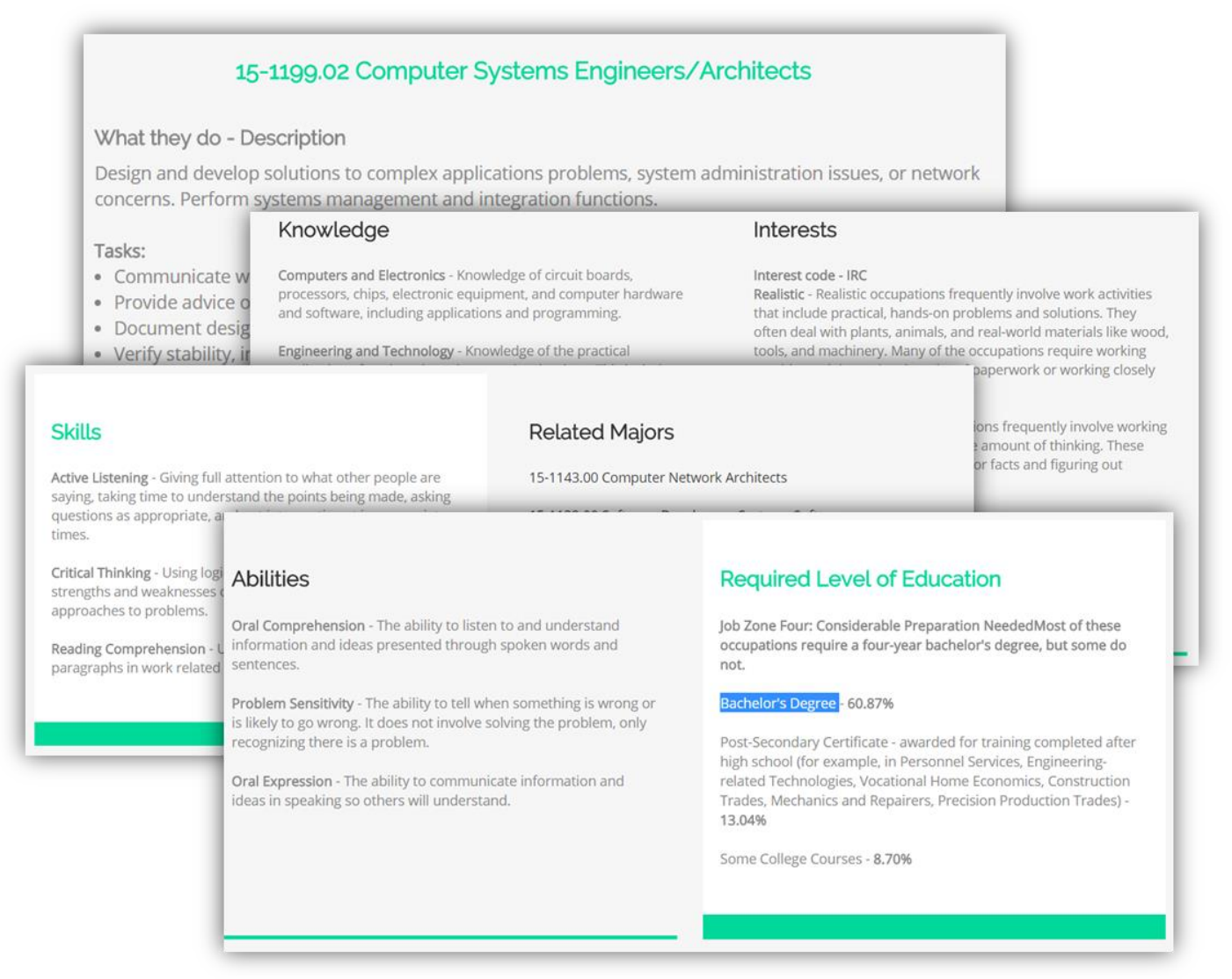

Figure 4: Sample of occupation description - Computer Systems Engineers/Architects.

\subsection{Methods}

In order to recommend suitable occupations to students based on their vocational interest, personality, and learning style, the collaborative filtering (CF) techniques are implemented. To do this, firstly we normalize data and secondly compute similarities. Then the predictions of factors are calculated if the factors are missing for the active student. Finally, the system executes modelbased algorithm to recommend the major to the active student. The model was constructed from regression model. 


\subsubsection{Memory-based CF}

It utilizes the entire student-factor database to generate a prediction. First, the system finds the similarity between all pairs of factors using a fuzzy similarity. Second, the system executes a recommendation stage. It uses the most similar factors to a student's already-scored factors to generate the prediction. This calculation is a weighted sum.

Prediction of missing factors: The system represents students' demographic information, intended major, scores of BFI, ILS and HC model (see Fig. 5) based on the answers of the questionnaire. The 3 inventories have totally 19 factors. But to fill those inventories are optional. At least, the one inventory should be taken. It means some factors could be blank. After the student fills the questionnaire, the system check missing scores of each factor for the active student. If there are the missing factors, the system predicts the scores of that factors, and shows the results. Methods are described below.

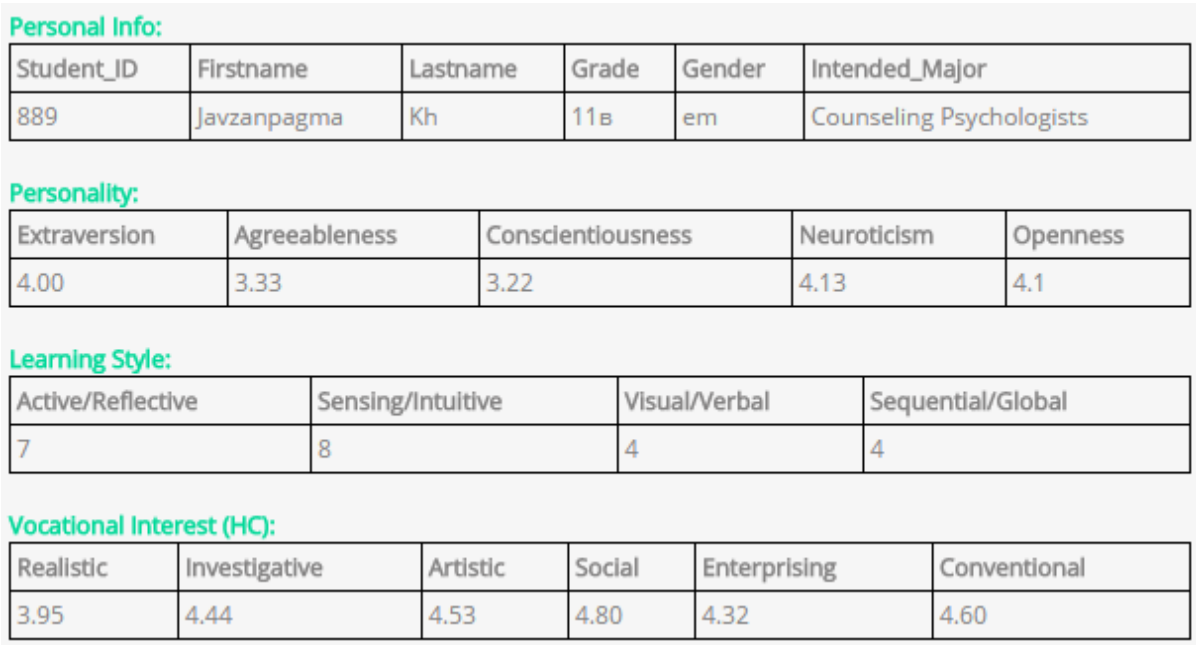

Figure 5: Example - Student 889's personal information, BFI, ILS, and HC scores

Data normalization. The scores in students' vocational interests and occupations' interests are different ranges. Hence, we utilize two methods namely, fuzzy logic and feature scaling, for normalizing data to convert it between 0 and 1 .

Fuzzy values. The scores could be ranged $[0,1]$ using fuzzy values that can be representing in graphical view which is a membership function using Trapezoid function. This scores will be used in Fuzzy similarity.

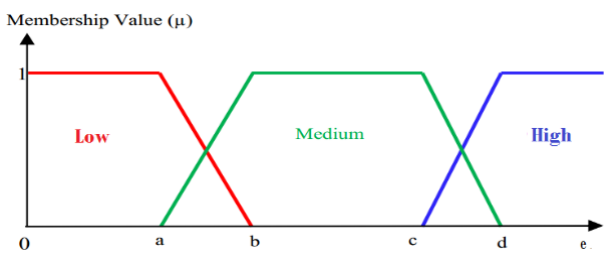

Figure 6: Membership function for interests of students and occupations

A membership function for occupational interest and students' interest in figure 6 on the discourse $\mathrm{x}$ is defined as $\mu C: \mathrm{x} \rightarrow[0,1]$ and $\mu S: \mathrm{x} \rightarrow[0,1]$. Equations (1) and (2) is use to convert all the crisp value from input where $\mathrm{a}<\mathrm{b}<\mathrm{c}<\mathrm{d}<\mathrm{e}$. For occupational interest $\mu C$ : $\mathrm{a}=3, \mathrm{~b}=4, \mathrm{c}=5, \mathrm{~d}=6$, $\mathrm{e}=7$. For student's interest $\mu S: \mathrm{a}=1, \mathrm{~b}=2, \mathrm{c}=3, \mathrm{~d}=4, \mathrm{e}=5$. 


$$
\mu C(x)=\left\{\begin{array}{lr}
1 & x<a \\
\frac{x-a}{b-a} & a \ll x \ll b \\
1 & b \ll x \ll c \\
\frac{d-x}{d-c} & c \ll x \ll d \\
1 & x>d
\end{array}\right.
$$

$$
\mu S(x)=\left\{\begin{array}{lr}
1 & x<a \\
\frac{x-a}{b-a} & \quad a \ll x \ll b \\
1 & b \ll x \ll c \\
\frac{d-x}{d-c} & c \ll x \ll d \\
1 & x>d
\end{array}\right.
$$

Similarity computation. We employed a Fuzzy similarity algorithm. Fuzzy similarity [36$38,41]$ measures similarity between item $i$ and $j$ is given by

$$
\operatorname{sim}(i, j)=\frac{\sum_{k=1}^{m} \min \left(x_{i k}, x_{j k}\right)}{\sum_{k=1}^{m} \max \left(x_{i k}, x_{j k}\right)}
$$

Where, $n$ is total numbers of occupation, $m$ is total number of factors in vocational interest, $i$ is the current student, $j$ is the counter of occupation, $x_{i}$ and $x_{j}$ are scores of student and occupation in interest, $\operatorname{sim}(i, j)$ is the result of pair wise comparison.

Prediction computation. Weighted sum method $[22,25,39,40]$ computes the prediction. Each rating is weighted by the corresponding similarity $S_{i, j}$ between items $i$ and $j . R_{u, i}$ is the rating of user $u$ on item $i$. Prediction $P_{u, i}$ as

$$
P_{u, i}=\frac{\sum_{\text {all similar items }, N}\left(s_{i, N} * R_{u, N}\right)}{\sum_{\text {all similar items }, N}\left(||_{i, N} \mid\right)}
$$

\subsubsection{Model-based CF}

The algorithms involve building a model based on the dataset of ratings. The model is developed using regression analysis to find patterns based on training data. Vocational interests (six factors - RIASEC) are predicted by using personality and learning style of students. The model can be seen in Table 2 .

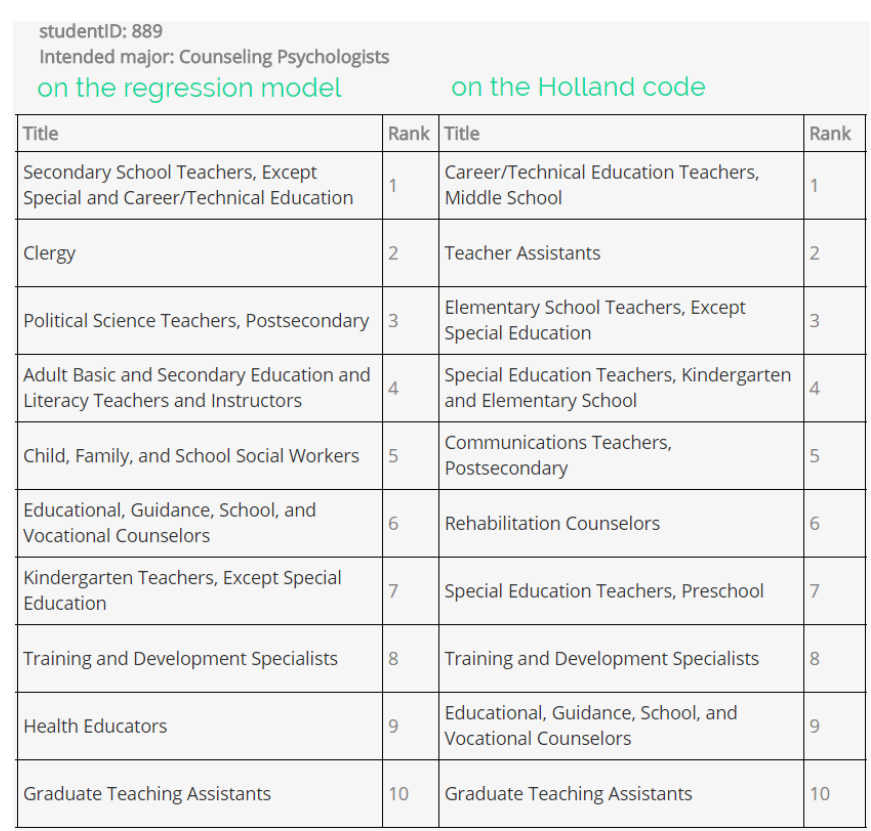

Figure 7: Top 10 occupation recommendation for student 889 using regression model and HC model.

To recommend top-N occupations using regression model, the system utilizes BFI and ILS with vocational interests to make a model. When students reply the questionnaires of BFI and ILS, they will receive 5 scores in personality and 4 scores in learning style. The reason is that every person belongs to all factors between low and high scores. Using those scores, the system 
calculates scores of six vocational interests respectively based on the regression model. Then the system computes similarities and shows top-N occupations. The result is shown in Figure 7.

Students reply the vocational interest questionnaire about what they like to do and then they will get 6 scores of vocational interests. Those scores are used to find out recommending occupations of HC model. Each occupation in dataset has six scores of vocational interests. In order to find the recommended occupations, the system first calculate similarities between active student's scores and occupational scores in vocational interests. After that, it retrieves top ten occupations based on the similarities to the active student (see Figure 7).

\section{Data Analysis}

Pearson's $\mathrm{r}$ correlation, and stepwise multiple regression analysis were calculated. Furthermore, basic statistical analysis techniques such as frequency and standard deviation of distribution were also employed. Cronbach alpha analysis was employed to compute the reliability. SPSS 20 statistical analysis software was used to analyze the data.

Two characteristics emerged as significant predictors of vocational interest of students. Those were learning styles and personalities. The dependent variable of the study is vocational interest scores of students (see Figure 8). The independent variables are the scores of learning styles and personalities of students. Correlations of the predicted, recommended, intended, and suggested majors.

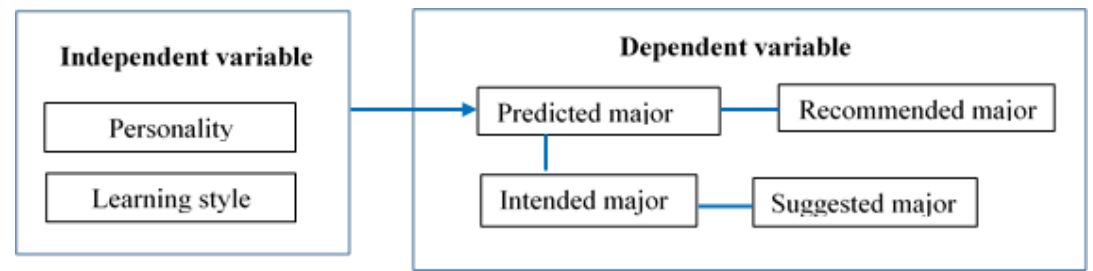

Figure 8: Independent and dependent variables in Regression model.

\subsection{Descriptive statistics}

Table 1 shows means and standard deviations of students' vocational interests, personalities, and learning styles.

\begin{tabular}{|c|c|c|c|c|c|c|c|c|c|c|c|c|c|c|c|}
\hline & \multicolumn{6}{|c|}{ Holland interests } & \multicolumn{5}{|c|}{ Big five personalities } & \multicolumn{4}{|c|}{ Learning styles } \\
\hline & 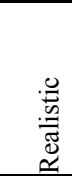 & 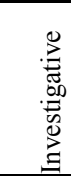 & 莣 & $\begin{array}{l}\overline{\text { J }} \\
\text { ס } \\
\text { n }\end{array}$ & 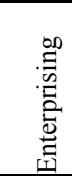 & $\begin{array}{l}\bar{\pi} \\
.0 \\
0 \\
0 \\
0 \\
0 \\
0\end{array}$ & 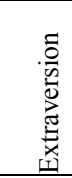 & 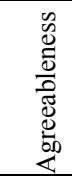 & 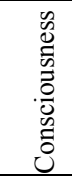 & 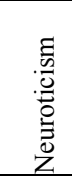 & 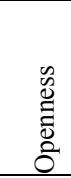 & 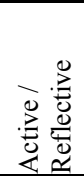 & 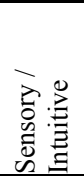 & 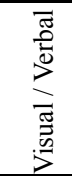 & 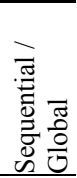 \\
\hline Mean & 3.53 & 3.59 & 3.75 & 3.93 & 3.53 & 3.61 & 3.57 & 3.45 & 3.34 & 3.08 & 3.45 & 7.21 & 7.48 & 6.39 & 6.74 \\
\hline SD & 0.58 & 0.59 & 0.63 & 0.57 & 0.6 & 0.64 & 0.54 & 0.43 & 0.55 & 0.63 & 0.49 & 1.77 & 1.71 & 2.21 & 2.03 \\
\hline
\end{tabular}

Table 1: Means and standard deviations of three models 


\subsection{Regression analysis}

\subsubsection{Stepwise regression model on Holland interests}

The stepwise regression was employed to explore the predictors of each vocational interest, namely, Realistic, Investigative, Artistic, Social, Enterprising, and Conventional based on the Big five personalities and learning styles of students as shown in Table 2.

\begin{tabular}{|c|c|c|c|c|c|c|c|c|c|c|c|c|}
\hline & \multicolumn{12}{|c|}{ Vocational interests (HC) } \\
\hline & \multicolumn{2}{|c|}{ Realistic } & \multicolumn{2}{|c|}{ Investigative } & \multicolumn{2}{|c|}{ Artistic } & \multicolumn{2}{|c|}{ Social } & \multicolumn{2}{|c|}{ Enterprising } & \multicolumn{2}{|c|}{ Conventional } \\
\hline & $B$ & $t$ & $B$ & $t$ & $B$ & $t$ & $B$ & $t$ & $B$ & $t$ & $B$ & $t$ \\
\hline \multicolumn{13}{|l|}{ BFI } \\
\hline Extraversion & & & & & & & .34 & $5.08^{* *}$ & .35 & $4.67 * *$ & & \\
\hline Agreeableness & & & & & & & .19 & $2.58^{*}$ & & & & \\
\hline Consciousness & & & & & & & .14 & $2.27 *$ & & & .35 & $4.62 * *$ \\
\hline Neuroticism & & & & & & & .27 & $5.06 * *$ & .20 & $3.43 *$ & .23 & $3.51 *$ \\
\hline Openness & .47 & $6.21 * *$ & .61 & $8.24 * *$ & .78 & $10.96^{* *}$ & .36 & $5.14 * *$ & .47 & $5.97 * *$ & .42 & $5.01 * *$ \\
\hline \multicolumn{13}{|l|}{ ILS } \\
\hline Active/Reflective & & & & & & & .07 & $4.14 * *$ & .04 & $2.08^{*}$ & .06 & $2.42 *$ \\
\hline Sensory/Intuitive & .06 & $2.57^{*}$ & & & & & & & & & & \\
\hline Visual/Verbal & .07 & $4.21 * *$ & 0.05 & $3.03 *$ & .06 & $4.01 * *$ & & & .03 & $2.03 *$ & .04 & $2.31 *$ \\
\hline Constant & 1.02 & $3.06^{*}$ & 1.17 & $4.31 * *$ & .66 & $2.52^{*}$ & -1.01 & $-2.58^{*}$ & -.44 & -1.24 & -.38 & -.94 \\
\hline $\mathrm{R}^{2}$ & \multicolumn{2}{|c|}{.270} & \multicolumn{2}{|c|}{.304} & \multicolumn{2}{|c|}{.436} & \multicolumn{2}{|c|}{.537} & \multicolumn{2}{|c|}{.451} & \multicolumn{2}{|c|}{.365} \\
\hline Adj $R^{2}$ & \multicolumn{2}{|c|}{.259} & \multicolumn{2}{|c|}{.297} & \multicolumn{2}{|r|}{.430} & \multicolumn{2}{|c|}{.522} & \multicolumn{2}{|c|}{.436} & \multicolumn{2}{|c|}{.347} \\
\hline $\mathrm{R}^{2}$ Change & \multicolumn{2}{|c|}{.026} & \multicolumn{2}{|c|}{.034} & \multicolumn{2}{|r|}{.049} & \multicolumn{2}{|c|}{.013} & \multicolumn{2}{|c|}{.012} & \multicolumn{2}{|c|}{.018} \\
\hline
\end{tabular}

Table 2: Stepwise regression between HC model's six scales, Big five personalities, and Learning styles. $N$ $=190 . * p<.05 .{ }^{* *} p<.01$.

We found that Openness factor in BFI, Sensory, Visual, and Intuitive factors in LS explained $27 \%$ of variance in Realistic interest $(\mathrm{F}=22.98)$; Openness factor, Visual and Verbal factors in ILS explained $30.4 \%$ of variance in Investigative interest $(\mathrm{F}=40.85)$; Openness factor, Visual, and Verbal factors explained $43.6 \%$ of variance in Artistic interest $(\mathrm{F}=72.28)$; Extraversion, Agreeableness, Conscientiousness, Neuroticism, and Openness factors in BFI, Active, and Reflective factors in ILS explained 53.7\% of variance in Social interest $(\mathrm{F}=35.34)$; Extraversion, Neuroticism, and Openness factors, Active, and Reflective factors explained $45.1 \%$ of variance in Enterprising interest $(\mathrm{F}=30.25)$; Conscientiousness, Neuroticism, and Openness factors with Active and Reflective factors in ILS explained 36.5\% variance in Conventional interest ( $\mathrm{F}=$ 21.12).

\subsubsection{Correlation between suggested, intended, predicted, and recommended majors}

Pearson's correlation is shown in Table 3 to explore the relationship between suggested major by parents, intended major of students, predicted major derived from regression model with personality and learning style, and recommended major by actual HC model through the highest three.

There is a strong relationship between suggested major by parents and intended major of students. 155 students answered that they discussed with parents about their choice of the major. 
Sixty-three students intended the same major as the parents suggested, whereas 87 students planned a different major than the major suggested by the parents.

\begin{tabular}{lcccc}
\hline \hline Majors & $\mathbf{1 .}$ & $\mathbf{2 .}$ & $\mathbf{3 .}$ & $\mathbf{4 .}$ \\
\hline 1. Suggested major by parents & 1 & & & \\
2. Intended major of students & $.362^{* *}$ & 1 & & \\
3. Predicted major & -.020 & $.164^{*}$ & 1 & \\
4. Recommended major by Holland model & .086 & .141 & $.228^{* *}$ & 1 \\
\hline \hline
\end{tabular}

Table 3: Pearson's correlations between suggested, intended, predicted, and recommended majors. ${ }^{*} p<$ $.05 . * * p<.01$.

Thirteen students had not decided the intended major by the time the survey was conducted. The predicted major has a moderate association with intended major and has a strong correlation with the recommended major by Holland model. In addition, students' high score is significantly correlated to student's favorite subject $(\mathrm{r}=0.278, \mathrm{p}<.01)$, predicted major $(\mathrm{r}=0.234, \mathrm{p}<.01)$, and intended major $(r=0.231, p<.01)$. Foreign language $(n=32)$ is the most favorite subject of the students followed physical education $(\mathrm{n}=24)$ and chemistry subjects $(\mathrm{n}=18)$. Physical education $(n=21)$ and technology subjects $(n=13)$ are the highest score subjects of students in this study.

To obtain a deeper understanding of the influences on the major choice of the students, we asked the questions shown in Table 4 from students. Seventy percentage of the students answered that they discussed with the parents before making the important decision. Though, 121 students replied that they would not follow the parent for the major choice if they do not like the suggested major by the parents. Some students answered that the suggested majors by the parents were the same as their intended majors, hence the students were more confident with their decisions.

To understand the reasons to select the intended major of the students, we asked a multiplechoice question in the questionnaire (third question of Table 4). Totally, 153 students answered this question. We noted from the students' answers that the answers "Easily finding a job" and "parent suggested" are the highest influenced reasons in choosing the intended major, followed by the answers "nowadays this major is popular" and "high salary". Not surprisingly, 130 students replied that they would decide the major choice based on their interest with other reasons. 23 students selected other options except "according to the interest". 78 students mentioned that the reason to select major choice was only their interest, while 75 students were influenced by the society and the environment in selecting their majors.

\begin{tabular}{|c|c|c|c|}
\hline Questions of the influence of the major choice of the student & Yes & No & Not filled \\
\hline $\begin{array}{l}\text { Will you discuss with your parents when you make a critical } \\
\text { decision? }\end{array}$ & $133(70 \%)$ & $20(10.5 \%)$ & $37(19.5 \%)$ \\
\hline $\begin{array}{l}\text { Will you follow the suggestion of your parent, if your parent } \\
\text { asks you to choose their suggested major, even you don't like? }\end{array}$ & $30(15.5 \%)$ & $121(64 \%)$ & $39(20.5 \%)$ \\
\hline Why did you choose this intended major? & & & $37(19.4 \%)$ \\
\hline According to my interest & 130 & & \\
\hline Easily finding a job & 41 & & \\
\hline Family (specially parent) suggested & 38 & & \\
\hline Nowadays this major is very popular & 32 & & \\
\hline High salary & 21 & & \\
\hline Teacher suggested & 3 & & \\
\hline My friends are going to choose & 0 & & \\
\hline
\end{tabular}

Table 4. Influence of the choice of the major 


\section{Experimental Result}

We demonstrated the Top-N occupation recommendation system using regression model which predict the vocational interests based on personality and learning style, and HC model employed experimental data from our questionnaire, which answered by students to measure the recommendations. Root Mean Square Error (RMSE) is to measure the prediction accuracy of the methods as well as the average absolute deviation between predicted ratings by recommender and user's real ratings. The experiment was evaluated on 190 users and 1000 occupations through 10 recommended occupations. The result is shown in Table 5. It can be observed from the results that Regression model in the total was given the lower value for this case. All the factors of Regression model are better result than $\mathrm{HC}$ model except $\mathrm{R}$ factor.

\begin{tabular}{llllllll}
\hline \hline Method & R & I & A & S & E & C & Total \\
\hline Regression Model & 0.22 & 0.12 & 0.06 & 0.08 & 0.13 & 0.11 & 0.1215 \\
HC Model & 0.17 & 0.13 & 0.11 & 0.09 & 0.14 & 0.12 & 0.1261 \\
\hline \hline
\end{tabular}

Table 5: Influence of the choice of the major. Lower value is better result. RMSE is used.

\section{Discussion and Conclusion}

Personality and learning style are both likely to play significant roles in influencing the major/occupation choice of the students. We built the occupation recommendation system (ORS) based on the vocational interests, personality, and learning style for guiding and counseling the students on their major/ occupation choice. One hundred ninety high school students from tenth to twelfth grades participated the experiment. We investigated predictors among Big five personalities and learning styles for vocational interests. Openness/Intellectual factor of Big five personality was positively related with all six vocational interests. Moreover, all Big five factors related with the social major. For the learning style, visual learning factor associated with all the vocational interests except the social major; while active learning factor related to social, enterprising, and conventional majors.

Meanwhile, we investigated the relationship between suggested major by parents, intended major of the students, predicted major derived from regression model among personalities and learning styles, and recommended major by actual HC model. From the association of those majors we found that there are some influences for major/occupation choices of students. Albeit the most of the students agreed in choosing the intended major as their own choice based on their interest or hobby, we noted that the parents adequately influenced the students for their major/occupation choices, followed by the factors "easily finding a job" and "high salary".

Several limitations of this study need to be addressed. The first limitation is the range of participants where a small size was selected which limited the generalization of results. The second limitation is a short period of this study. If the duration of the experiment is extended, we perhaps can find that the effectiveness of the proposed system on students' learning. The last limitation relates to some other possible ways, such as answering the questions without pay attention or following by others, which could influence the recommendations in their major choice.

In conclusion, the result indicated that personality, learning style, and vocational interest could be utilized for the guidance and the recommendation of the suitable occupations/majors of Mongolian students. In the future, we are going to map each occupation/major into relevant college/university curriculum as well as its courses. In addition, Open Educational Resource will 
be applied in the current system to provide more useful information to the students. Besides, students' the major/occupation choice from both rural and urban area of Mongolia will be explored; the students' satisfaction of the recommendation and the usefulness of ORS will be examined.

Acknowledgments. I sincerely thank to Prof. Hwang and W. G. C. W. Kumara for their great comments and suggestions. Furthermore, I am deeply grateful to Ch. Enkhtuul who is a teacher at Mongolian high school, for spending a lot of her valuable time in discussing issues in the major choice of her students as well as conducting the survey and counselling her students in the major choice using our system.

\section{References}

[1] Ferry, N. M. (2006). Factors influencing career choices of adolescents and young adults in rural Pennsylvania. Journal of Extension, 44(3), 1-6.

[2] Gordon, V. N. (2007). The undecided college student: An academic and career advising challenge. Charles C Thomas Publisher.

[3] Porter, S. R., \& Umbach, P. D. (2006). College major choice: An analysis of person-environment fit. Research in Higher Education, 47(4), 429-449.

[4] Cano, J. (1999). The relationship between learning style, academic major, and academic performance of college students. Journal of Agricultural Education, 40(1), 30-37.

[5] Calkins, L., \& Welki, A. (2006). Factors that influence choice of major: why some students never consider economics. International Journal of Social Economics, 33(8), 547-564.

[6] Arcidiacono, P., Hotz, J. V., \& Kang S. (2012). Modeling college major choices using elicited measures of expectations and counterfactuals. Journal of Econometrics, 166(1), 3-16.

[7] Al-Rfou, A. N. (2013). Factors that influence the choice of business major evidence from Jordan. IOSR Journal of Business and Management (IOSR-JBM), 8(2), 104-107.

[8] Sovet, L., \& Metz, A. (2014). Parenting styles and career desicion-making among French and Korean adolescents. Journal of Vocational Behavior, 84(3), 345-355.

[9] Fouad, N. A., Kim, S. Y., Ghosh, A., Chang, W. H., \& Figueiredo, C. (2015). Family Influence on Career Decision Making Validation in India and the United States. Journal of Career Assessment, 1069072714565782.

[10] Aguado, C. L., Laguador, J. M., \& Deligero, J. C. (2015). Factors affecting the choice of school and students' level of interest towards the Maritime Program. Asian Social Science, 11(21).

[11] McCrae, R. R., \& John, O. P. (1998). An Introduction to the five-factor model and its applications. Personality: critical concepts in psychology, 60, 295.

[12] Carless, S. A. (1999). Career assessment: Holland's vocational interests, personality characteristics, and abilities. Journal of Career Assessment, 7(2), 125-144.

[13] Ibrahimoglu, N., Unaldi, I., Samancioglu, M., \& Baglibel, M. (2013). The relationship between personality traits and learning styles: a cluster analysis. Asian Journal of Management Sciences and Education, 2(3), 93-108.

[14] Hussain, S., Abbas, M., Shahzad, K., \& Bukhari, S. A. (2012). Personality and Career choices. African Journal of Business Management , 6(6), 2255-2260.

[15] Brown, D., \& Cinamon, R. G. (2015). Contribution of personality to self-efficacy and outcome expectations in selecting a high school major among adolescents with learning disabilities. Career Development and Transition for Exceptional Individuals, 2165143415587689. 
[16] Solomon, B. A., \& Felder, R. M. (1999). Index of learning styles. Raleigh, NC: North Carolina State University. Available online.

[17] Felder, R. M., \& Spurlin, J. (2005). Applications, Reliablity and Valitdy of the Index of learning styles. International Journal of Engineering Education, 21(1), 103-112.

[18] Hawk, T. F., \& Shah, A. J. (2007). Using learning style instruments to enhance student learning. Decision Sciences Journal of Innovative Education, 5(1), 1-19.

[19] Holland, J. L., \& Gottfredson, G. D. (1992). Studies of the hexagonal model: An evaluation: or the perils of stalking the perfect hexagon. Special Issue: Holland's theory. Journal of Vocational Behavior, 40, 158-170.

[20] De Fruyt, F., \& Mervielde, I. (1997). The five-factor model of personality and Holland's RIASEC interest types. Journal of Personality and Individual Differences, 23(1), 87-103.

[21] Woods, S. A., \& Hampson, S. E. (2010). Predicting Adult Occupational Environments from Gender and Childhood Personality Traits. Journal of Applied Psychology, 95(6), 1045.

[22] Su, X., \& Khoshgoftaar, T. M. (2009). A survey of collaborative filtering techniques. Advances in artificial intelligence, 2009, 4.

[23] Verbert, K., Manouselis, N., Ochoa, X., Wolpers, M., Drachsler, H., Bosnic, I., \& Duval, E. (2012). Contextaware recommender systems for learning: a survey and future challenges. Learning Technologies, IEEE Transactions on, 5 (4), 318-335.

[24] Bobadilla, J., Ortega, F., Hernando, A., \& Gutiérrez, A. (2013). Recommender systems survey. Knowledge-Based Systems, 46, 109-132.

[25] Sarwar, B., Karypis, G., Konstan, J., \& Riedl, J. (2001, April). Item-based collaborative filtering recommendation algorithms. In Proceedings of the 10th international conference on World Wide Web (pp. 285-295). ACM.

[26] Koren, Y., \& Bell, R. (2015). Advances in collaborative filtering. In Recommender Systems Handbook (pp. 77118). Springer US.

[27] S.Enkhtuvshin. (2013). Suraltsagchdad ajil mergejliin chig barimjaa olgoj bui baidaliin sudalgaa. [The research on providing occupational orientation for the students].

[28] B.Bolormaa, B.Oyunsuren, Ch.Altengerel, \& Ch.Tsolmon. (2015). Akhlakh angiin suragchdiin mergejil songoltin ontslogiig sudalsan dungees. [The research result in career guidance of high school students]. Innovation, 9(3). Retrieved from innovations.mn

[29] Goldberg, L. R. (1992). The development of markers for the Big-Five factor structure. Psychological Assessment, 4(1), 26.

[30] Goldberg, L. R. (1993). The structure of phenotypic personality traits. American Psychologist, 48(1), 26.

[31] Holland, J. L. (1997). Making vocational choices: A theory of vocational personalities and work environments . Psychological Assessment Resources.

[32] Peterson, N. G., Mumford, M. D., Borman, W. C., Jeanneret, P. R., Fleishman, E. A., Levin, K. Y., ... \& Gowing, M. K. (2001). Understanding work using the Occupational Information Network (O* NET): Implications for practice and research. Personnel Psychology, 54(2), 451-492.

[33] Hilton, M. L., \& Tippins, N. T. (Eds.). (2010). A Database for a Changing Economy: Review of the Occupational Information Network $\left(O^{*} N E T\right)$. Washington: National Academies Press.

[34] O*NET Resource Center. (2015). The $O * N E T$ analyst database. O*NET Consortium.

[35] Morgan, R. L. (1991). Classification of instructional programs.

[36] Cha, S. H. (2007). Comprehensive survey on distance/similarity measures between probability density functions. City, 1(2), 1. 
[37] Razak, Tajul Rosli, Muhamad Arif Hashim, Norliza Mohd Noor, Abd Halim, Iman Hazwam, and Nur Fatin Farihin Shamsul. "Career path recommendation system for UiTM Perlis students using fuzzy logic." InIntelligent and Advanced Systems (ICIAS), 2014 5th International Conference on, pp. 1-5. IEEE, 2014.

[38] Baccour, Leila, Adel M. Alimi, and Robert I. John. "Some notes on fuzzy similarity measures and application to classification of shapes, recognition of Arabic sentences and mosaic." IAENG International Journal of Computer Science 41, no. 2 (2014): 81-90.

[39] Ochirbat, A., Shih, T. K., Chootong, C., Sommool, W., Gunarathne, W. K. T. M., Wang, H. H., \& Ma, Z. H. (2017). Hybrid occupation recommendation for adolescents on interest, profile, and behavior. Telematics and Informatics.

[40] Ochirbat, A., \& Lin, H. (2016). Major Recommendation for Students based on Vocational Interests. In Proceedings of the 9th IEEE International Conference On Ubi-Media Computing" Umedia-2016" (pp. 60-65).

[41] Shaout, Adnan, and Jaldip Trivedi. "Performance appraisal system using a multistage fuzzy architecture." International Journal of Computer and Information Technology (ISSN: 2279-0764) Volume (2013). 